\author{
DE DE GRUYTER \\ OPEN \\ 10.1515/aucft-2016-0017
}

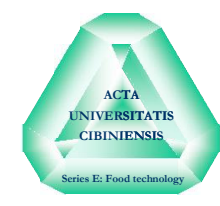

\title{
EFFECTS OF SPORTS NUTRITIONAL BEVERAGES CONTAINING GLYCERINUM ON THE PHYSICAL FUNCTIONS OF BICYCLISTS AFTER PHYSICAL ACTIVITIES
}

\author{
Xiaodong CHEN, Yang YU ${ }^{1}$ \\ P. E. Department in Heilongjiang University of Science and Technology, \\ Haerbing, Heilongjiang, 150022, China
}

\begin{abstract}
This study aimed at providing a reference for the selection of energy tonics for sportsmen engaging in high-strength training and competitions by investigating the effects of the intake of beverages containing glycerinum before exercise at high temperature on the physical functions of bicyclists. Forty bicyclists were selected as research subjects and divided into a test group and a control group. The indexes such as urine volume, weight loss value, oxyhemoglobin saturation, blood lactic acid, nervous tension difference value and reaction time were detected after the sportsmen took different beverages. The conclusions were drawn after the data were analyzed by SPSS ver. 18.0. The research results demonstrated that, the intake of beverages containing glycerinum could reduce urine output and lower weight loss value, prolong the endurance riding time of bicyclists in high temperature environment, reduce the concentration of blood lactic acid, improve the aerobic exercise ability of sportsmen, relieve nervous tension and fatigue, and improve physical functions.
\end{abstract}

Keywords: Glycerinum; sports nutritional beverage; exercise capacity; physical functions

\section{INTRODUCTION}

Bicycling as a cyclic high-strength sports event requires strictly on the physical ability of sportsmen (Stepanova et al., 2011). During high-strength sports, bicyclists tend to have constantly increased thermal load and inhibited physical heat dissipation under the effect of high temperature; thus dehydration is of high risks if bicyclists continue to attend training and competition (Singh, 2005). To prevent the adverse effect caused by

\footnotetext{
${ }^{1}$ Corresponding author. Mailing address: P. E. Department in Heilongjiang University of Science and Technology No.2468, Puyuan Road, Songbei District, Harbin, Heilongjiang, China. Email: sk6759@163.com
} 
dehydration on the exercise capacity of sportsmen, water is usually supplemented before exercise. Goulet (2009) thought that, water retention in human body was inversely proportional to interval time; the shorter the interval time, the more the water retention in the bodies of sportsmen. Rasmussen et al. (2010) held that, oxyhemoglobin saturation is lower with the increase of exercise intensity. Currently, there are many sports beverages available in market; however, few sports beverages are prepared in a scientific way and have good effects (Field et al., 2014). Good sports beverages have a huge impact on sportsmen as it not only can improve the exercise capacity and regulate physical functions of sportsmen, but also can relieve fatigue (Cebi, 2015).

This study investigated the effects of the supplement of sports beverages containing glycerinum before exercise on the physical functions and exercise capacity of sportsmen by comparing various indexes of 20 bicyclists who were supplemented with sports beverages containing glycerinum before exercise and 20 bicyclists who were supplemented with sports beverages without containing glycerinum before exercise. This work aimed at providing a reference and theoretical basis for the supplement of beverages containing glycerinum in exercise practice.

\section{MATERIALS AND METHOD}

\section{Test subjects and materials}

Forty male bicyclists aged 25 to 30 years old were selected from cycling clubs. They had no chronic diseases and had years of riding experience. All the subjects signed informed consent. They were randomly divided into a control group (A) and a test group (B). The basic conditions of the subjects are shown in Table 1.The major test instruments used in the test are shown in Table 2. Besides, a competitive ability diagnosis and evaluation system and a low-oxygen and high-temperature environment training testing system were also needed.

Beverages provided for the control group were prepared by blending sports beverage with drinking water in a certain proportion, while beverages provided for the test group were prepared by blending sports beverages with a certain amount of glycerinum (the beverage was not harmful to the body). Glycerinum is a kind of three-carbon alcohol which releases energy by means of oxidation (Huang et al., 2015). Glycerinum can save glycogen, prolong the time of endurance exercise, and delay exercise induced fatigue (Wan, et al., 2014). A study has suggested that, supplementing sports beverages containing glycerinum has remarkable effect in improving water storage capacity, reducing urine output, and delaying dehydration, thus it could effectively 
improve the exercise capacity of sportsmen (Hillyer, et al., 2015). The sugar concentration of the sports beverages used in this study was lower than $8 \%$, thus the sugar can be absorbed by blood (Currell, and Jeukendrup, 2008).

Table 1. Basic data of the subjects

\begin{tabular}{lll}
\hline & Test group $(\mathrm{n}=20)$ & Control group $(\mathrm{n}=20)$ \\
\hline Age & $25.5 \pm 5.62$ & $25.5 \pm 5.62$ \\
\hline Height $(\mathrm{cm})$ & $176.23 \pm 5.58$ & $176.23 \pm 5.58$ \\
\hline Weight $(\mathrm{Kg})$ & $71.86 \pm 12.38$ & $71.68 \pm 12.52$ \\
\hline
\end{tabular}

Table 2. Instruments used

\begin{tabular}{|c|c|c|c|}
\hline Name & Type & Supplier & City/country \\
\hline Cycle ergometer & EC3000 & $\begin{array}{l}\text { Shanghai Mingyuan Industrial } \\
\text { Co., Ltd. }\end{array}$ & $\begin{array}{l}\text { Shanghai, } \\
\text { China }\end{array}$ \\
\hline Pulse oximeter & CMS50E & $\begin{array}{l}\text { Contec Medical Systems } \\
\text { Co., Ltd. }\end{array}$ & $\begin{array}{l}\text { Qinhuangdao } \\
\text {, China }\end{array}$ \\
\hline $\begin{array}{l}\text { Thermal infrared } \\
\text { imager }\end{array}$ & FLIR T104 & $\begin{array}{l}\text { Shanghai Pumeng Photoelectric } \\
\text { Technology Co., Ltd. }\end{array}$ & $\begin{array}{l}\text { Shanghai, } \\
\text { China }\end{array}$ \\
\hline $\begin{array}{l}\text { Blood lactate } \\
\text { analyzer }\end{array}$ & $\begin{array}{l}\text { M9- } \\
\text { LT1710 }\end{array}$ & $\begin{array}{l}\text { Beijing Medwest Broad Science } \\
\text { and Technology Co., Ltd. }\end{array}$ & $\begin{array}{l}\text { Beijing, } \\
\text { China }\end{array}$ \\
\hline Urine analyzer & IRICELL & Beckman Coulter Co., Ltd. & Miami, USA \\
\hline $\begin{array}{l}\text { Body composition } \\
\text { tester }\end{array}$ & DBA-210 & $\begin{array}{l}\text { Donghuayuan Medical } \\
\text { Equipment Co., Ltd. }\end{array}$ & $\begin{array}{l}\text { Beijng, } \\
\text { China }\end{array}$ \\
\hline
\end{tabular}

\section{Test methods}

Before experiment, the urine, body composition, body temperature, oxygen desaturation degree, heart rate and blood lactate level of the subjects were detected. Then the subjects in the test group were supplemented with a kind of sports beverage containing glycerinum, while the subjects in the control group were given a kind of nutritional beverage which contained the same components as the beverage taken by the test group except glycerinum. Finally, the above indexes were detected. The detection methods were as follows:

(1) Detection of urine: the urine of the subjects was dropped on test papers and then detected for urine specific gravity, urine acid-base property, urine protein, urine sugar, ketone body, nitrite, bilirubin, occult blood, urobilinogen and white blood cells respectively by a urine analyzer. The results were printed.

(2) Detection of body composition: the water content, naked weight and muscle content of the subjects were measured using a body composition analyzer before supplement, after supplement, and after exercise. The results 
were printed. The content of water, naked weight and muscle content of the subjects in the control group was $(53 \pm 1.4) \%,(73.18 \pm 2.51) \mathrm{kg}$ and $(38 \pm$ $1.2) \%$ respectively, and the corresponding data of the test group was $(52 \pm$ $1.5) \%,(72.88 \pm 2.55) \mathrm{kg}$ and $(38 \pm 1.1) \%$ respectively.

(3) Detection of body temperature of sportsmen: temperature test was performed on the fixed position of the faces of the subjects using a thermal infrared imager. The testing time was recorded. The facial temperature of the subjects in the test group and the control group was $(36.7 \pm 1.5){ }^{\circ} \mathrm{C}$ and $(36.8$ $\pm 1.4)^{\circ} \mathrm{C}$ respectively, and the time was recorded as 9:15.

(4) Detection of blood lactic acid: The probe of a pulse oximeter was connected to the finger of the subject, then bound up, and fixed. Then the indexes such as heart rate and oxyhemoglobin saturation were measured.

(5) Detection of blood lactic acid: A small quantity of finger tip blood was taken and detected by a blood lactate analyzer before exercises and after a period of training. The results were recorded timely.

\section{Design of exercise after the supplement of nutritional sports beverages}

The beverage for the sportsmen in the test group was prepared using 1.5 $\mathrm{ml} / \mathrm{kg}$ fruit vitamin, $20 \mathrm{ml} / \mathrm{k}$ drinking water and $1 \mathrm{~g} / \mathrm{kg}$ glycerinum according to the weight. As to the control group, the components were the same except glycerinum. Bicyclists rode cycle ergometers in a sitting position in a frequency of $60 \mathrm{r} / \mathrm{min}$. When the power of the cycle ergometer reached $60 \mathrm{~W}$, the power increased by $30 \mathrm{~W}$ every ten min, till the sportsmen exhausted. The indexes were detected every five minutes during exercise. Besides, the indexes were also detected immediately at the end of exercise; the exhaustion time and the maximum power were recorded. The subjects were considered as exhausted when their heart rates reached the highest values, they were unable to ride in a specified frequency, the concentration of blood lactic acid was higher than $8 \mathrm{mmol} / \mathrm{L}$, and the subjective fatigue degree became the highest (Cinar et al, 2009).

The temperature was kept at $35 \pm 2{ }^{\circ} \mathrm{C}$ during testing. The index changes of the subjects after drinking the beverage containing glycerinum could be known by comparing the data measured in the two times of testing.

\section{Detection of subjective fatigue, aerobic capacity, nervous fatigue and reaction time}

Borg subjective fatigue scale was put in the visual range of the subjects during exercise. Each subject selected a number corresponding to fatigue every time when the load increased by one level; and the results were recorded. After exercise, the subjects lay flat. Limb lead electrode holders and chest lead suckers were smeared using ethyl alcohol. During testing, coupling 
agents which could benefit the transmission of signals and eliminate noise was smeared between the electrode holder and the chest lead sucker (Smale, 2009). Whether the electrode slices, electrode holders and suckers were connected at the correct testing positions was checked; during testing, the subjects should keep relaxed and breathe evenly. Besides, the head, heart and waists of each subject were connected with electrodes. The computer system could obtain the results of central nervous system efficiently after data acquisition.

\section{Statistical processing}

SPSS ver. 18.0 was used to statistically analyze the data of the sportsmen. Difference was considered as statistically significant if $\mathrm{p}<0.05$ and as highly significant if $\mathrm{p}<0.01$.

\section{RESULTS AND DISCUSSION}

\section{Effect of glycerinum on weight}

The weight changes of the control group A and B are shown in Table 3.It could be observed that the weight of group A and B had no remarkable difference before and after exercise, but the sportsmen in the both groups showed a significant decline of weight (the reduction degree of group A and $\mathrm{B}$ was different). The change of the weight in group $\mathrm{A}$ and $\mathrm{B}$ had obvious difference $(p<0.01)$. Thus it could be concluded that, the subjects in the both groups had dehydration, and the dehydration amount of group B was lower than that of group A.

Table 3. Weight change of group A and B

\begin{tabular}{lccc}
\hline & $\begin{array}{l}\text { Naked weight } \\
\text { before exercise }(\mathrm{kg})\end{array}$ & $\begin{array}{l}\text { Naked weight after } \\
\text { exercise }(\mathrm{kg})\end{array}$ & $\begin{array}{l}\text { Weight change } \\
\text { value }(\mathrm{kg})\end{array}$ \\
\hline Control group (A) & $73.18 \pm 2.51$ & $71.68 \pm 2.55$ & $1.50 \pm 0.10$ \\
\hline Test group (B) & $72.88 \pm 2.55$ & $72.16 \pm 2.46$ & $0.72 \pm 0.10$ \\
\hline P value & 0.508 & 0.145 & 0.001 \\
\hline
\end{tabular}

\section{Effect of glycerinum on urine output}

Urine output change of the sportsmen in group A and B is shown in Table 4.

Table 4. Urine output change of the sportsmen in group A and B

\begin{tabular}{ccc}
\hline & Urine output after exercise $(\mathrm{ml})$ & Total urine output $(\mathrm{ml})$ \\
\hline Group A & $315.56 \pm 39.15$ & $548.46 \pm 49.08$ \\
\hline Group B & $212.06 \pm 24.86$ & $447.75 \pm 57.68$ \\
\hline p value & 0.033 & 0.033 \\
\hline
\end{tabular}


The urine output of sportsmen in group B was obviously lower than that in group A. Paired T test showed that, the urine output of the sportsmen in the two groups had a significant difference $(p<0.05)$. Thus it could be concluded that, the supplement of beverages containing glycerinum before exercise reduced the urine output of the subjects to some extent.

\section{Effect of glycerinum on the duration of endurance exercise}

The change of the duration of endurance exercise of group A and B is shown in Table 5. Results demonstrates that, the duration of exercise of the subjects who took the beverage containing glycerinum before exercise was much longer than that of those who took placebo before exercise $(p<0.01)$. It suggested that, the intake of beverages containing glycerinum before exercise could effectively prolong exercise time. It might be because that, the added glycerinum which reduced urine output and increased water storage content delayed the occurrence of dehydration, prolonged exercise time, and improved exercise capacity.

Table 5. Change of the duration of endurance exercise in group A and B

\begin{tabular}{ll}
\hline & Duration of exercise (min) \\
\hline Group A & $42.78 \pm 7.88$ \\
\hline Group B & $45.95 \pm 9.22$ \\
\hline p value & 0.003 \\
\hline
\end{tabular}

\section{Effect of glycerinum on oxyhemoglobin saturation}

The average value of the oxyhemoglobin saturation of the subjects who took different kinds of beverages before exercise is shown in Figure 1.

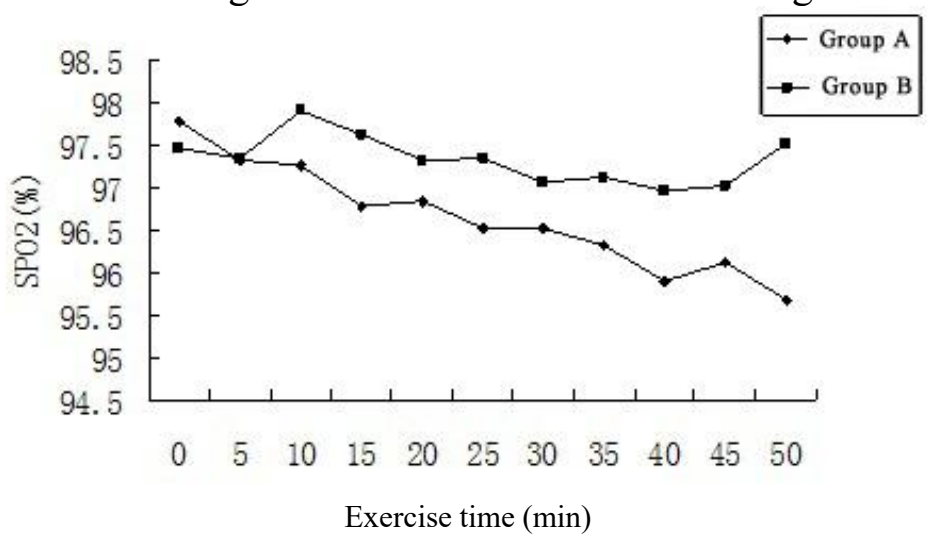

Figure 1. Variation of oxyhemoglobin saturation of group A and B during exercise

Figure 1 shows that, from the beginning of exercise to the 5th min, the difference of oxyhemoglobin saturation between the two groups was not 
statistically significant $(p>0.05)$; in the 10th $\min$, the oxyhemoglobin saturation of group B became higher than that of group A, and the difference had statistical significance $(\mathrm{p}<0.05)$; in the 20th min, though the oxyhemoglobin saturation of group B was still high than that of group A, the difference was not statistically significant $(p>0.05)$; the difference became highly remarkable in 40th min $(\mathrm{p}<0.01)$.It suggested that, the intake of beverages containing glycerinum before exercise could relieve the exercise induced artery blood oxygen decrease to some extent and the relief degree fluctuated in the whole process of exercise.

\section{Effect of glycerinum on blood lactic acid}

The blood lactate concentration change of the subjects in group A and B in a static state before exercise and immediately after exercise is shown in Table 6 . The blood lactate concentrations of the sportsmen in group B in a static state and immediately after exercise were both obviously lower than those of group $\mathrm{A}$, and the differences between the two groups were statistically significant $(p<0.05)$. It suggested that, under the same load, the accumulated amount of lactic acid in the bodies of sportsmen in the test group was less and the supplement of the beverage containing glycerinum before exercise improved the aerobic exercise ability of the sportsmen to some extent.

Table 6. Change of blood lactic acid in groups A and B

\begin{tabular}{lll}
\hline & Static $\mathrm{L}(\mathrm{mmol} / \mathrm{L})$ & Immediately after exercise $\mathrm{L}(\mathrm{mmol} / \mathrm{L})$ \\
\hline Group A & $3.12 \pm 0.88$ & $7.55 \pm 3.05$ \\
\hline Group B & $2.89 \pm 0.81$ & $6.25 \pm 2.68$ \\
\hline p value & 0.325 & 0.028 \\
\hline
\end{tabular}

\section{Effect of glycerinum on influence factors of neuromodulation system}

Vagus nerve can slow down heart rate and decrease blood pressure, and its change can reflect the fatigue degree of nerve. The effect of sympathetic nerve is opposite to the effect of vagus nerve. Strengthened sympathetic nerve can promote blood circulation system, accelerate heart rate, and improve blood pressure (Mastaglia, 2012; Wallin and Charkoudian, 2007; Hayashi, 2011). The changes of sympathetic nerve and vagus nerve in group $A$ and $B$ are shown in Table 7 . The influence factors of vagus nerve regulating system of group A and B reduced remarkably after exercise, and the difference between before exercise and after exercise was highly significant $(p<0.01)$; the influence factors of sympathetic nerve regulating system of group A and B significantly increased after exercise, and the difference between before exercise and after exercise was highly significant $(\mathrm{p}<0.01)$, but the difference between the two groups had no statistical significance. Thus it 
suggested that, the exercise load designed in the test fatigued the nervous systems of the sportsmen in the both groups, but the fatigue of the nervous system of the sportsmen taking beverages containing or not containing glycerinum had no statistically significant difference.

Table 7. Change of influence factors of vagus nerve and sympathetic nerve in groups A and B

\begin{tabular}{|l|l|l|l|}
\hline \multicolumn{2}{|c|}{} & Group A & Group B \\
\hline \multirow{2}{*}{$\begin{array}{l}\text { Influence factors of } \\
\text { vagus nerve }\end{array}$} & Before exercise & $0.22 \pm 0.09$ & $0.23 \pm 0.11$ \\
\cline { 2 - 4 } & After exercise & $0.15 \pm 0.10$ & $0.15 \pm 0.10$ \\
\cline { 2 - 4 } & P value & 0.000 & 0.009 \\
\hline \multirow{2}{*}{$\begin{array}{l}\text { Influence factors of } \\
\text { sympathetic nerve }\end{array}$} & Before exercise & $42.62 \pm 13.18$ & $49.33 \pm 19.82$ \\
\cline { 2 - 4 } & After exercise & $64.88 \pm 20.72$ & $65.15 \pm 22.52$ \\
\cline { 2 - 4 } & P value & 0.000 & 0.011 \\
\hline
\end{tabular}

\section{Effect of glycerinum on energy metabolism system}

Sportsmen energy metabolism system evaluation includes aerobic capacity and anaerobic capacity (Casas, et al, 2012). The changes of aerobic capacity index and anaerobic capacity index of the subjects in group A and B are shown in table 8 .

Table 8. Change of aerobic capacity and anaerobic capacity indexes of groups A and B

\begin{tabular}{ccccc}
\hline & & Group A & Group B & $\mathrm{p}$ value \\
\hline Aerobic capacity & Before exercise & $117.66 \pm 9.28$ & $117.95 \pm 8.65$ & 0.655 \\
\cline { 2 - 5 } index test & After exercise & $116.73 \pm 10.56$ & $116.13 \pm 9.88$ & 0.418 \\
\hline $\begin{array}{c}\text { Anaerobic capacity } \\
\text { index test }\end{array}$ & Before exercise & $136.62 \pm 10.03$ & $135.30 \pm 7.86$ & 0.506 \\
\cline { 2 - 5 } & After exercise & $136.75 \pm 8.26$ & $133.82 \pm 7.01$ & 0.008 \\
\hline
\end{tabular}

Table 8 shows that, the aerobic capacity of the sportsmen slightly reduced after exercise, but there was no significant difference; the anaerobic capacity of group B showed a decreasing tendency compared to that of the control group before exercise, but there was no significant difference; the anaerobic capacity index of group A remarkably decreased after exercise, and the difference was highly significant in statistics $(p<0.01)$. The reason for the changes might be associated to the significant decrease of anaerobic capacity of the sportsmen in the test group due to the long exercise time.

\section{Effect of glycerinum on reaction time}

Reaction time of the subjects in the two groups is shown in Table 9.The reaction time of group A was basically consistent before and after exercise; the reaction time of group B decreased significantly after exercise; the reaction time of the two groups was basically consistent before exercise, but 
the reaction time of group B was much shorter than that of group A after exercise, and the difference had statistical significance $(p<0.05)$. Thus it suggested that, the subjects who took sports beverages containing glycerinum before exercise had increased attention and rapid reaction during exercise.

Table 9. Change of reaction time of groups A and B

\begin{tabular}{lll}
\hline & Reaction time before exercise (s) & Reaction time after exercise (s) \\
\hline Group A & $0.172 \pm 0.018$ & $0.172 \pm 0.016$ \\
\hline Group B & $0.168 \pm 0.014$ & $0.165 \pm 0.011$ \\
\hline $\mathrm{p}$ value & 0.696 & 0.048 \\
\hline
\end{tabular}

\section{CONCLUSION}

In this study, 20 bicyclists took sports beverages containing glycerinum before exercise and the other 20 bicyclists took sports beverages not containing glycerinum. The effects of the intake of beverages containing glycerinum before exercise on the water storage capacity of human body were investigated by comparing indexes such as weight loss value, urine output, duration of endurance exercise, oxyhemoglobin saturation, blood lactic acid, reaction time and energy metabolism. The test results demonstrated that, the intake of sports beverages containing glycerinum could reduce urine output, reduce weight loss, improve aerobic exercise ability, prolong the endurance riding time of bicyclists in hot and humid environment, relieve fatigue and optimize body mechanism. This work provides a theoretical reference and basis for the supplement of beverages containing glycerinum in sports practices.

\section{ACKNOWLEDGEMENT}

Heilongjiang higher education and teaching project: practical study on sports protection curriculum optimization counter-measures, Grant No.: JG2013010502.

\section{REFERENCES}

1. Casas J., Pincebourde S., Mandon N., Vannier F., Poujol R., \& Giron D. (2012). The effect of glycerol supplements on aerobic and anaerobic performance of athletes and sedentary subjects. Journal of Human Kinetics, 34(1):69-79.

2. Cebi M. (2015). The effect of sports drinks and water consumption on electrolyte levels of football players. Studies on Ethno-Medicine, 9(2):197-201.

3. Cinar V., Mogulkoc R. \& Baltaci A.K. (2009). Calcium supplementation and 4-week exercise on blood parameters of athletes at rest and exhaustion. Biological Trace Element Research, 134(2):130-5. 
4. Currell K., Jeukendrup A. E. (2008). Superior endurance performance with ingestion of multiple transportable carbohydrates. Medicine \& Science in Sports \& Exercise, 40(2):275-81.

5. Field A.E., Sonneville K.R., Falbe J., Flint A., Haines J., Rosner B., \& Camargo C.A. (2014). Association of sports drinks with weight gain among adolescents and young adults. Obesity, 12(10):112-113.

6. Goulet E.D. (2009). Review of the effects of glycerol-containing hyperhydration solutions on gastric emptying and intestinal absorption in humans and in rats. International Journal of Sport Nutrition \& Exercise Metabolism, 19(5):547-560.

7. Hayashi Y. (2011). Control of Sympathetic Nerve Activity and Cardioprotection. JJSCA, 31:098-106.

8. Hillyer M., Menon K., Singh R., Hillyer M., \& Menon K. (2015). The Effects of Dehydration on Skill-Based Performance. International Journal of Sports Science, 5(3):99-107.

9. Huang X., Wu H. \& Yao W. (2015).The Study of the Effect of Glycerolcontaining Beverages Drinking Method before Exercise in the Environment of High Temperature and High Humidity.

10. Mastaglia F.L. (2012). The relationship between muscle pain and fatigue. Neuromuscular Disorders, 22(22):S178-S180.

11. Rasmussen P., Overgaard A., Bjerre A.F., Bjarrum M., Carlsson C., Petersen N.C., Nielsen H.B., \& Volianitis S. (2010). The effects of normoxia, hypoxia, and hyperoxia on cerebral haemoglobin saturation using near infrared spectroscopy during maximal exercise. International Journal of Industrial Ergonomics, 40(2):190-196.

12. Singh R. (2005). Nutritional requirements of athletes exercising in the hot environment. Malaysian Journal of Nutrition, 11(2):189-198.

13. Smale M. (2009). Waveform phase shift study to compute the relationship between the mason-likar and the standard limb lead electrode placements. Computers in Cardiology, 1(1017):721-724.

14. Stepanova G.P., Skedina M.A., Degterenkova N.V., Kashenkova L.A., \& Voronkov Y.I. (2011). Diagnostic screening of the human myocardium during the bicycle exercise test. Human Physiology, 37(7):916-921.

15. Wallin B.G. \& Charkoudian N. (2007). Sympathetic neural control of integrated cardiovascular function: Insights from measurement of human sympathetic nerve activity. Muscle \& Nerve, 36(5):595-614.

16. Wan N.R.W.I., Ramli Z.A.C., \& Ismail M. (2014). Recovery and Purification of Crude Glycerol from Vegetable Oil Transesterification. Separation \& Purification Reviews, 44(3):250-267. 